\title{
Avaliadores Ad Hoc
}

Agradecemos aos avaliadores e avaliadoras ad hoc desta edição:

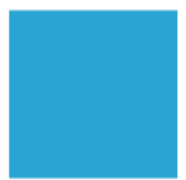

Revista

Extensão em Foco
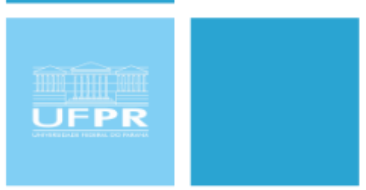

ISSN $2358-7180$

Loriane Trombini Frick

Tiago Venturi

Mabel Arantes

Danilene Gullich Donin Berticelli

Katherinne Maria Spercoski

Roberta Chiesa Bartelmebs

Guilherme Ruela

Matheus Alpes

Margarete Maciel

Maria Gislene Fonseca

Rita de Cássia dos Anjos

Robson Simplício de Sousa

Camila Tonezer

Lucas Albuquerque do Nascimento

Mara Fernanda Parisoto

Vinícius Rufino Leal 